\title{
Is executive impairment associated with schizophrenic syndromes? A meta-analysis
}

\author{
C. R. M. Dibben ${ }^{1}$, C. Rice ${ }^{2}$, K. Laws ${ }^{3}$ and P. J. McKenna ${ }^{4,5 *}$ \\ ${ }^{1}$ Fulbourn Hospital, Cambridge, UK \\ ${ }^{2}$ Institute of Psychiatry, De Crespigny Park, Denmark Hill, London, UK \\ ${ }^{3}$ School of Psychology, University of Hertfordshire, Hatfield, UK \\ ${ }^{4}$ Benito Menni CASM, Barcelona, Spain \\ ${ }^{5}$ CIBERSAM, Spain
}

Background. A key neuropsychological proposal in schizophrenia is that negative and disorganization symptoms are associated with different patterns of impairment on executive tasks.

Method. Studies reporting correlations between positive, negative or disorganization symptoms and any type of executive test were meta-analysed. The influence of moderating factors was also examined, including age, treatment and stage of illness and whether symptoms were relapsing or persistent. The magnitudes of the correlations were compared with those for general intellectual impairment.

Results. Pooled correlations between executive impairment and both negative symptoms and disorganization were significant in the small-to-moderate range. That for positive symptoms ('reality distortion'), however, was close to zero. The pattern of correlations among different executive tests differed significantly for negative symptoms and disorganization. Patients with stable clinical pictures showed significantly higher correlations with executive impairment than those with relapsing and remitting illnesses. Both negative symptoms and disorganization also correlated significantly with general intellectual function as indexed by current IQ.

Conclusions. Meta-analysis supports the view that negative symptoms and disorganization are associated with partially dissociable patterns of executive impairment. However, co-existent general intellectual impairment has been an important confounding factor in the studies to date.

Received 27 September 2007; Revised 28 April 2008; Accepted 8 May 2008; First published online 30 June 2008

Key words: Executive function, neuropsychology, schizophrenia, schizophrenic symptoms.

\section{Introduction}

Based on functional imaging studies (e.g. Heinz et al. 2004; Hill et al. 2004) and to some extent on neuropathological findings (e.g. Harrison \& Lewis, 2003), the frontal lobes are widely believed to be a key area of brain dysfunction in schizophrenia. Almost as widespread is the belief that they are responsible for some of the symptoms of the disorder. Thus, authors such as Liddle (1987a) and Weinberger (1988) have proposed that the negative symptoms of schizophrenia are essentially the same phenomenon as the apathy and emotional indifference seen in the frontal lobe syndrome. Liddle (1987a) and others (e.g. McGrath, 1991; Chaika, 1996) have also proposed that an executivetype dysfunction affecting speech might give rise to

* Address for correspondence: Dr P. J. McKenna, Benito Menni Complex Assistencial en Salut Mental, Germanes Hospitalàries del Sagrat Cor de Jesús, C/Doctor Antoni Pujades 38-C, 08830 Sant Boi de Llobregat, Barcelona, Spain.

(Email : mckennapeter1@googlemail.com) formal thought disorder, for example by causing poor planning of discourse and/or an inability to inhibit inappropriate verbal responses. Similar concepts run through the most fully articulated theory of schizophrenic symptoms to date, Frith's (1992) integrative cognitive neuropsychological account. He also argues that certain positive symptoms such as passivity and auditory hallucinations could reflect a specialized form of frontal/executive impairment, the inability to monitor willed intentions.

Although there are several potential ways of testing the 'frontal lobe' hypothesis of schizophrenic symptoms, investigation has mainly taken place at the neuropsychological level. Such studies have examined the correlations between scores on different classes of schizophrenic symptoms and impairment on one or more measures of executive function. Typically, they find significant correlations with negative symptoms and disorganization, but not with 'reality distortion', that is delusions and hallucinations (for reviews see Liddle, 2001; Donohoe \& Robertson, 2003 ; McKenna \& 
Oh, 2005). However, a number of studies, some with large sample sizes, have either had negative findings (e.g. Joyce et al. 2002) or have found significant correlations with only a minority of the executive tests used (e.g. Mohamed et al. 1999; O'Leary et al. 2000). Another problem is that these studies commonly also find associations between negative symptoms and/or disorganization and impairment on non-executive tests (see McKenna \& Oh, 2005).

Drawing on a distinction between 'apathetic' and 'disinhibited' clinical pictures seen in neurological patients with the frontal lobe syndrome, Liddle $(1987 a, 2001)$ has further proposed that negative and disorganization symptoms are not just associated with executive impairment but that they show different patterns of associations with different executive tests. According to Liddle, negative symptoms should be particularly associated with difficulty on tasks that require the generation of responses, for example verbal fluency, whereas disorganization should be associated with impairment on tasks such as the Stroop test, where prepotent responses have to be inhibited. Liddle \& Morris (1991) found some support for these distinct patterns of correlation, but the dissociation was not complete. Considerable overlap in the pattern of associations of negative and disorganization symptoms with different executive tests was also found by Donohoe \& Robertson (2003) and McKenna \& Oh (2005) in their reviews.

Existing reviews of clinical-neuropsychological correlations have mostly been of the narrative or 'vote counting' variety (e.g. Liddle, 2001; Donohue \& Robertson, 2003; McKenna \& Oh, 2005). One metaanalysis has been carried out (Nieuwenstein et al. 2001), but this only pooled data from studies using a single executive test, the Wisconsin Card Sorting Test (WCST). The aim of this systematic review was therefore to provide a comprehensive examination of the relationship between executive impairment and schizophrenic symptoms using meta-analytic techniques.

\section{Method}

Papers reporting neuropsychological data in relation to schizophrenic symptoms were searched electronically. The earliest dates used were the defaults for Medline (1980), PsycINFO (1985) and EMBASE (1980), and the search was carried out up to March 2008. Studies were identified using the key words 'schizophrenia' and related terms, 'negative symptoms', 'positive symptoms', 'poverty syndrome', 'disorganization', 'delusions', 'hallucinations', 'formal thought disorder', and 'deficit schizophrenia'. These were combined with 'frontal lobe', 'executive function', 'frontal cortex', 'neuropsychological tests', 'cognition', 'working memory' and 'memory short-term'. We also entered the acronyms for symptom scales such as SANS, SAPS, BPRS and PANSS, and the names of commonly used executive tests, such as the Wisconsin Card Sorting Test, Stroop, verbal fluency, Tower of London/Hanoi, Trail Making Test, digit span (for reverse digit span) and the Cognitive Estimates Test.

The electronic search was supplemented by checking book chapters and review articles on the neuropsychology of schizophrenia, and the reference lists of all papers reporting relevant data. Finally, the names of chief investigators of known first-episode studies of schizophrenia were also searched electronically, as these studies typically include detailed neuropsychological assessments. Both English- and foreignlanguage papers were included. Unpublished studies were not included but publication bias was examined.

The same databases were searched over the same period for the supplementary meta-analysis of symptoms and overall intellectual function, for which current IQ was used as a measure (see below). Here the search terms used were IQ, intelligence, intelligence tests, intellect and general intellectual ability.

To be included studies had to report data on adult patients meeting any diagnostic criteria for schizophrenia. Studies where some of the patients had a diagnosis of schizo-affective disorder were also included. Studies reporting findings on adolescents or where the sample consisted only of patients over 65 were excluded. Studies were required to assess symptoms using a published rating scale [e.g. the Brief Psychiatric Rating Scale (BPRS), Manchester Scale, Positive and Negative Syndrome Scale (PANSS), Positive and Negative and Disorganized Symptoms Scale (PANADSS), Schedule for Affective Disorders and Schizophrenia (SADS), Scales for the Assessment of Positive and Negative Symptoms (SAPS, SANS), Thought, Language and Communication (TLC) scale for formal thought disorder, High Royds Evaluation of Negativity (HEN) and Iager scales for negative symptoms].

The analysis was based on scores on Liddle's three syndromes, hereafter referred to as positive ('reality distortion', delusions and hallucinations), negative ('psychomotor poverty') and disorganization (thought disorder and inappropriate affect with some authors also including bizarre behaviour). Where individual classes of symptoms were reported separately (e.g. delusions and hallucinations or individual SANS subscale scores for affective flattening, alogia, anhedonia-asociality, etc.), the relevant correlations were averaged, providing these permitted a reasonable approximation to the full range of symptoms in a particular syndrome. 
Table 1. Types of executive tests included in the meta-analysis

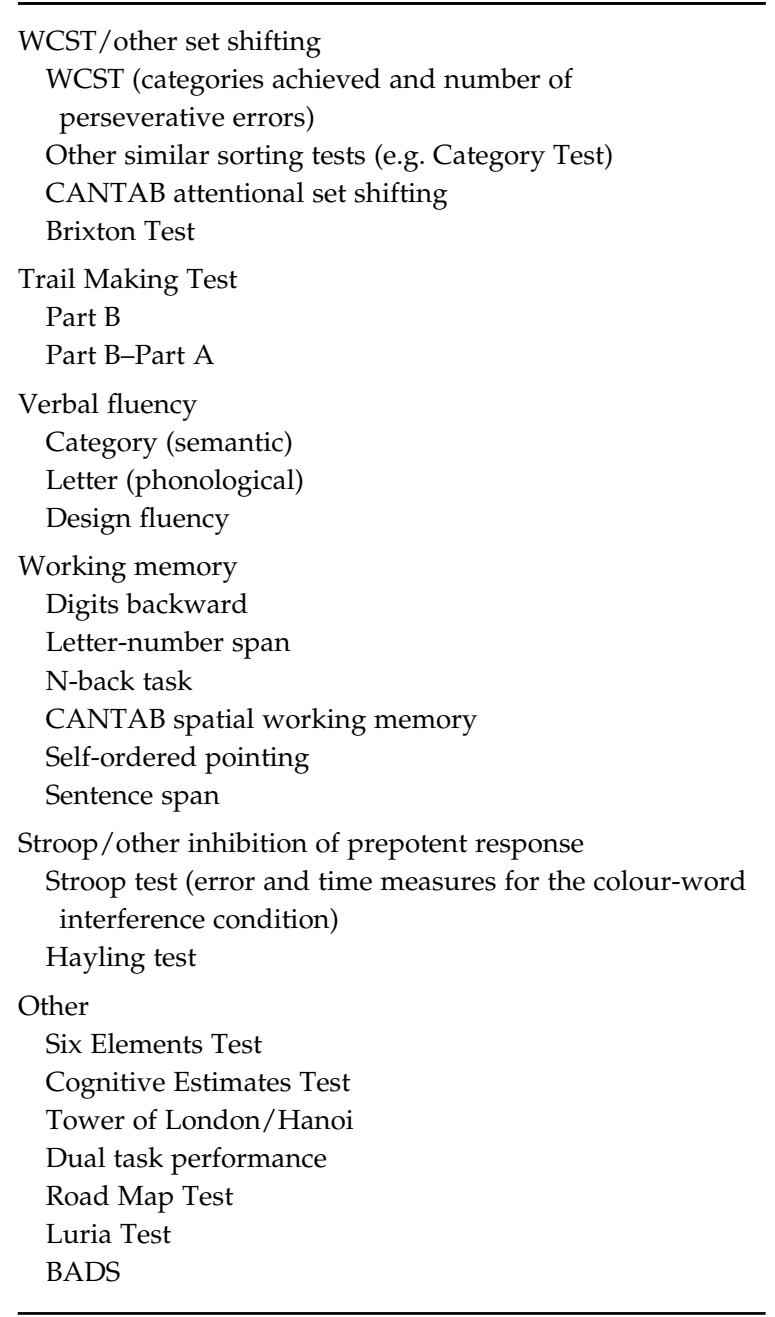

WCST, Wisconsin Card Sorting Test; CANTAB, Cambridge Neuropsychological Test Automated Battery; BADS, Behavioural Assessment of the Dysexecutive Syndrome.

Exclusions: studies reporting only WCST percentage perseverative errors were not included as this measure can be criticized (see Laws, 1999). Studies reporting only Trail Making Test part A time, or time for both parts A and B together, were also not included. The Continuous Performance Test and other vigilance tests were also excluded (see text).

Studies that only reported partial symptom data (e.g. correlations for delusions only or hallucinations only) were excluded. During the course of the metaanalysis, however, a relative lack of studies reporting correlations with disorganization became apparent, and so it was decided to also include studies reporting only formal thought disorder. This was on the grounds that this is arguably the main constituent of disorganization (inappropriate affect is an uncommon symptom and authors often do not include bizarre behaviour as part of the syndrome).

Several studies, rather than reporting correlations for positive, negative and disorganization symptoms, reported correlations for the older, dichotomous concept of positive and negative symptoms. The concept of positive symptoms was broader in these studies, encompassing delusions, hallucinations and formal thought disorder. Accordingly, it was not possible to include these studies in the meta-analysis of the correlates of positive or disorganization symptoms. However, their data for negative symptoms could still usually be included. For this reason there were many more studies in the meta-analysis of negative symptoms.

The neuropsychological inclusion and exclusion criteria are summarized in Table 1 . Only tests considered to be executive within the current cognitive meaning of the term were included. Hence, we included working memory tasks only if they engaged the central executive component of Baddeley's (1986) model of working memory (i.e. those requiring manipulation rather than just holding of information in short-term memory); as a result, forward span tests were not included. Tasks that are known to activate the prefrontal cortex but do not have any executive component in the neuropsychological sense were not included (e.g. long-term memory tasks, vigilance tasks). Where studies reported composite measures of executive function, these were only included if a majority of the contributing tests were executive according to the above definition.

We included studies that reported both Pearson and Spearman correlations. Studies reporting partial correlations were excluded, unless the raw correlations could be obtained from the authors. Where data were reported but could not be extracted, the authors were contacted by email. A small number of studies, rather than reporting correlations between syndrome scores and neuropsychological test performance, provided data on two groups of patients, typically those with high and low scores on negative symptoms or 'deficit' and 'non-deficit' patients. Such data can be used to provide a correlation coefficient by calculating the effect size $(d)$ for the difference between the high and low symptom groups, and then converting this to $r$, which is mathematically related to $d$. This procedure yields a point biserial correlation, which was used in preference to the also derivable biserial correlation, as the latter makes assumptions about the normality of the distribution (see Howell, 1997).

Calculations were performed using D-STAT 1.10 (Johnson, 1993), which uses a fixed-effects model, and Comprehensive Meta-Analysis v.2 (Borenstein et al. 2006), where the fixed-effects option was again used. 


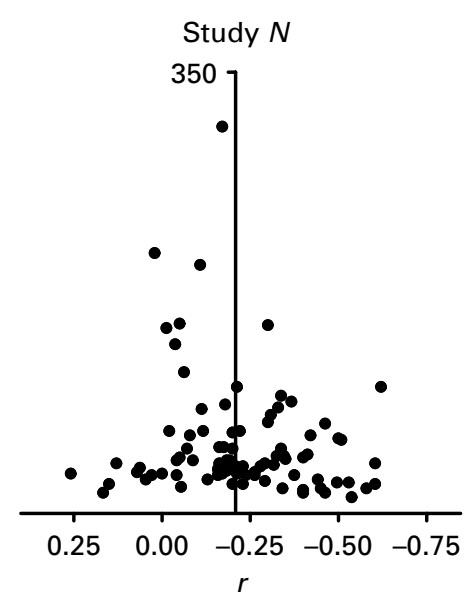

Negative symptoms

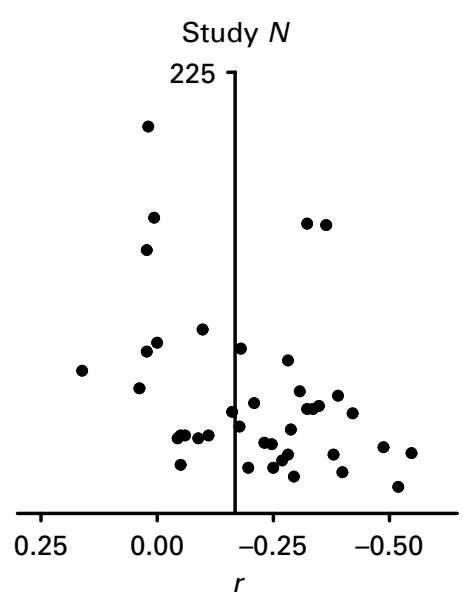

Disorganization

Fig. 1. Funnel plots of the correlations between executive test scores and negative symptoms and disorganization.

Homogeneity was examined using the $Q$ statistic and QB was used to test for significant differences between mean effect sizes. Various moderating variables were examined including age, length of illness, treatment status and type of executive task. Carpenter et al. (1988) have drawn a distinction between transient negative symptoms in schizophrenia (i.e. present at the height of an acute episode) and those that are enduring ('deficit' symptoms in Carpenter's terminology), with the latter being proposed to have a greater implication of poor outcome and being more closely related to underlying neurobiological mechanisms. In a similar vein, Liddle (1987a) and Baxter \& Liddle (1998) suggested that patients with persistent symptoms show higher correlations with neuropsychological test impairment than those who have relapsing and remitting illnesses. Therefore, we also examined stability of symptoms as a moderator variable.

The question of the specificity of the association between symptoms and executive impairment was examined by carrying out a supplementary metaanalysis of the correlations between positive, negative and disorganization symptoms and general intellectual impairment. For this purpose current IQ was chosen, as this was by far the most commonly used measure in the studies. Included here were studies reporting Wechsler Adult Intelligence Scale (WAIS)/ WAIS-R/WAIS-III full-scale IQ or verbal or performance IQ. We did not include studies reporting only single WAIS subtest scores, but if correlations on three or more subtest scores were provided these were averaged to approximate an index of overall IQ. We also included other current IQ measures including the Quick Test, Raven's Matrices, and armed forces aptitude tests.

\section{Results}

Correlations of clinical syndromes with executive test impairment

Eighty-eight studies were found that included usable data. These used a range of different executive tests. The purpose of this initial analysis was to establish the correlations between positive, negative and disorganization syndromes and a broad index of executive impairment. Therefore, studies reporting any measure of executive function were included in the analysis. Where a study reported multiple correlations with different executive test scores, these were averaged to provide a composite correlation.

Eighty-one papers reporting 83 studies included data on the executive correlates of negative symptoms. The pooled $r$ for these studies was -0.21 [95\% confidence interval $(\mathrm{CI})-0.24$ to -0.18$]$. The studies were significantly heterogeneous $[Q(82)=321.84, p<0.0001]$. Homogeneity was achieved by excluding 21 studies; this left the pooled effect size similar at -0.20 (CI -0.23 to -0.17$)$.

The effect size for 40 studies examining the correlates of disorganization was -0.17 (CI -0.21 to $-0.13)$. These data were heterogeneous $[Q(39)=$ $148.14, p<0.0001]$. Homogeneity was achieved by excluding eight studies, and this increased the pooled $r$ to -0.28 (CI -0.33 to -0.23$)$.

At +0.01 (CI -0.04 to +0.05$)$, however, the pooled $r$ for 34 studies of positive symptoms was negligible. These studies were again heterogeneous $[Q(33)=110.43, p<0.0001]$, but removing four outlying studies had little effect on the pooled $r(+0.02$, CI -0.03 to +0.07 ).

Funnel plots of the correlations for negative symptoms and disorganization are shown in Fig. 1. It can 
Table 2. Significant pooled correlations between negative and disorganization syndromes and different executive tests

\begin{tabular}{lllll}
\hline & $\begin{array}{l}r(95 \% \mathrm{CI}) \\
\text { negative symptoms }\end{array}$ & $\begin{array}{l}\text { No. of } \\
\text { studies }\end{array}$ & $\begin{array}{l}r(95 \% \mathrm{CI}) \\
\text { disorganization }\end{array}$ & $\begin{array}{l}\text { No. of } \\
\text { studies }\end{array}$ \\
\hline WCST, set shifting & $-0.16(-0.20$ to -0.13$)$ & 43 & $-0.19(-0.24$ to -0.14$)$ & 19 \\
Trails B & $-0.24(-0.29$ to -0.18$)$ & 24 & $-0.31(-0.40$ to -0.22$)$ & 10 \\
Verbal fluency & $-0.27(-0.31$ to -0.23$)$ & 40 & $-0.11(-0.17$ to -0.05$)$ & 18 \\
Working memory & $-0.14(-0.22$ to -0.07$)$ & 13 & $-0.12(-0.23$ to -0.00$)$ & 6 \\
Stroop/Hayling & $-0.13(-0.21$ to -0.05$)$ & 16 & $-0.29(-0.38$ to -0.21$)$ & 10 \\
\hline
\end{tabular}

CI, Confidence interval; WCST, Wisconsin Card Sorting Test.

be seen that the correlations for negative symptoms were fairly evenly distributed around both sides of the overall effect size (with a small number of studies finding better performance with higher negative symptom scores). However, for disorganization there was an obvious absence of studies with small sample sizes that failed to find significant correlations, suggesting publication bias.

\section{Moderating factors}

Age did not moderate the clinical-neuropsychological correlations for negative symptoms ( $n=80$ studies, $Z=0.37, p=0.71$ ) and was marginally significant for disorganization ( $n=40$ studies, $Z=-1.96, p=0.05$ ) (correlations were higher in older patients). Duration of illness did not significantly moderate the size of the correlation between negative symptoms and executive impairment ( $n=72$ studies, $Z=-1.08, p=0.28)$, but it did for disorganization $(n=36$ studies, $Z=-3.39$, $p=0.0006)$; correlations were higher in studies on patients with longer duration of illness.

Treatment moderated the pooled correlation for negative symptoms $[r$ for 58 studies on treated patients $=-0.19$ v. -0.29 for seven studies on untreated patients, $\mathrm{QB}(1)=6.28, p=0.01]$. This was also true for disorganization [ $r$ for 27 studies on treated patients $=-0.22 v .-0.14$ for five studies on untreated patients, $\mathrm{QB}(1)=4.09, p=0.04]$. However, it should be noted that in both analyses the number of studies carried out on untreated patients was small.

As mentioned earlier, Liddle (1987a) and Baxter \& Liddle (1998) have suggested that correlations between negative symptoms and neuropsychological test impairment may be more marked in patients with persistent symptoms than in those who have relapsing and remitting illnesses. To examine this issue, we dichotomized studies into those carried out on patients with 'acute/remitting' symptoms and those on patients with 'stable/persistent' symptoms. Patients in the former category were described in terms such as 'acute', 'acutely ill' or 'relapsed'; studies on in-patients described as stabilized or just prior to

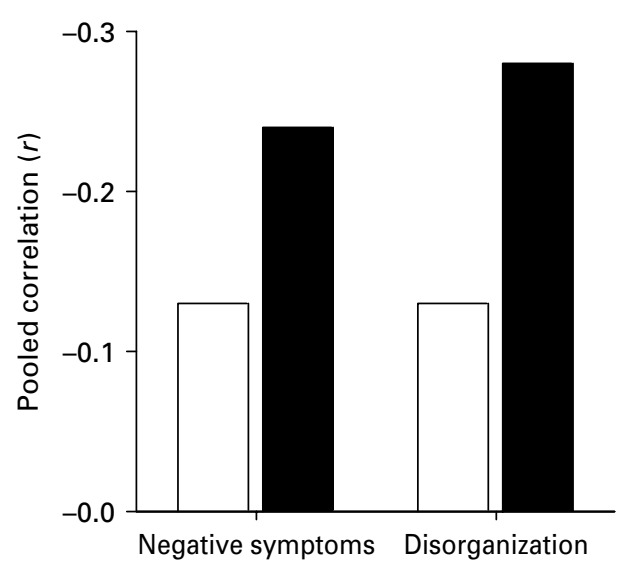

Fig. 2. Pooled correlations between negative symptoms and executive impairment and disorganization and executive impairment in studies carried out on patients with 'acute/ remitting' ( $\square$ ) and 'stable/persistent' ( $\square$ ) symptoms.

discharge were excluded. Studies in the latter category were carried out on out-patients, or on chronically hospitalized patients, if it was also specified that they were in a clinically stable condition. This distinction significantly moderated the correlations with negative symptoms [ $r$ for 19 studies on acute/remitting patients $=-0.13 v$. -0.24 for 35 studies carried out on stable/persistent patients, $\mathrm{QB}(1)=20.93, p<0.0001]$. It also significantly moderated the correlations with disorganization [ $r$ for 11 studies on acutely relapsed patients $=-0.12 v$. -0.28 for 16 studies carried out on stable patients, $\mathrm{QB}(1)=18.46, p<0.0001]$. The findings are illustrated in Fig. 2.

\section{Correlations with different executive tests}

The correlations between negative symptoms and disorganization and the five main categories of executive tests identified in Table 1 are shown in Table 2. For both negative symptoms and disorganization there was significant heterogeneity among the correlations [negative symptoms: $\mathrm{QB}(4)=42.27$; disorganization: $\mathrm{QB}(4)=33.71$, both $p<0.001$ ], indicating that there was significant variation among the 
correlations with the five types of tests. For negative symptoms the correlations ranged from -0.27 on verbal fluency and -0.24 on the Trail Making Test, part B down to -0.14 on working memory and -0.13 on the Stroop test. For disorganization the range was similar, from -0.31 on the Trail Making Test, part B down to -0.12 on working memory and -0.11 on verbal fluency.

It can be seen from Table 2 that verbal fluency impairment was nearly three times more strongly associated with negative symptoms than with disorganization $(-0.27 v$ v -0.11$)$. This difference was significant $[\mathrm{QB}(1)=40.44, p<0.0001]$. Impairment on the Stroop Test, by contrast, was twice as highly correlated with disorganization as it was with negative symptoms $(-0.29 v .-0.13)$, with the difference again being significant $[\mathrm{QB}(1)=8.29, p=0.004]$.

\section{Correlations between clinical syndromes and IQ}

The pooled correlation between IQ and negative symptoms in 30 studies was -0.21 (CI -0.26 to $-0.17)$, rising to -0.23 (CI -0.28 to -0.17 ) after six outliers were removed. The pooled correlation between IQ and disorganization was -0.21 (CI -0.28 to $-0.14)$. This increased to -0.28 (CI -0.35 to -0.19$)$ after excluding two outlying studies.

\section{Discussion}

This meta-analysis found that negative schizophrenic symptoms and disorganization, but not positive symptoms, are significantly associated with impairment on executive tests. Insofar as executive tests index frontal lobe function, meta-analysis therefore provides support for the view that frontal dysfunction underlies these two classes of symptoms. At the same time, at -0.20 and -0.28 (homogenized) respectively, the correlations were modest, falling between the 'rule-of-thumb' values of 'small' (0.1) and 'medium' (0.3). These values are broadly in keeping with those of an earlier meta-analysis by Nieuwenstein et al. (2001), who found a pooled correlation of -0.27 with negative symptoms in 15 studies and of -0.25 with disorganization in six studies using the WCST, but no significant correlation with positive symptoms (pooled $r$ of -0.04 ) in four studies. As Nieuwenstein et al. (2001) pointed out, this means that symptom dimensions account for less than $10 \%$ of the variance in performance on executive tests in schizophrenia, and suggests that any relationship between symptoms and underlying pathophysiological abnormality is relatively remote. Further caution is necessary in interpreting the relationship between disorganization and executive impairment, where we found that there was evidence of publication bias.
Nevertheless, significant moderating factors were identified in our meta-analysis, indicating that the associations may be stronger in some types of patient. High correlations between executive impairment and negative symptoms and/or disorganization have been a feature of several studies carried out on chronically hospitalized patients (e.g. Liddle \& Morris, 1991; Brown \& White, 1992), whereas correlations have sometimes been low or negligible in studies of firstepisode patients (e.g. Mohamed et al. 1999; Joyce et al. 2002; Rund et al. 2004). However, there are numerous exceptions to this rule and our meta-analysis did not find robust evidence that duration of illness was a moderating factor: it was significant for disorganization but not for negative symptoms. When the studies were divided according to a somewhat related distinction, into those carried out on patients with relapsing and remitting symptoms versus those with stable, persistent symptoms, a clearer moderating effect emerged that applied to both negative symptoms and disorganization. It seems that schizophrenic patients with established, relatively unchanging clinical pictures - one definition of chronicity - show stronger associations between symptoms and neuropsychological deficits than those whose symptoms come and go in acute attacks.

Why this should be so is not known. However, it is a theme that has surfaced before in the literature. Over 50 years ago, Kleist (Fish, 1957; Kleist, 1960) argued that the initially somewhat amorphous presentations of schizophrenia crystallized into a large number of stable states as the disorder evolved, each of which was dominated by one or a few symptoms that reflected dysfunction in a particular brain area. For Kleist, the end states of 'drive poor catatonia' (roughly equivalent to negative symptom schizophrenia) and hebephrenia were psychiatric analogues of the apathetic and disinhibited forms of the frontal lobe syndrome respectively. More recently, Carpenter and co-workers (Carpenter et al. 1988; Kirkpatrick et al. 2001) have argued that pathophysiological correlates of negative symptoms are most evident in patients who have enduring symptoms of this type, and have elevated this into the principle of a conceptual separation of deficit and non-deficit forms of schizophrenia. Liddle and co-workers (Liddle, 1987a); Liddle et al. 1992; Baxter \& Liddle, 1998) have also argued that different pathological processes might underlie symptoms, particularly negative symptoms, in chronic and remitting illnesses.

The other main moderating factor identified in this meta-analysis was neuroleptic treatment, where we found higher correlations in treated patients. However, the fact that there were few studies on untreated patients $(7 / 83$ in the case of negative 
symptoms and 5/40 in the case of disorganization) suggests this finding should be interpreted with caution.

A supplementary meta-analysis revealed that both negative symptoms and disorganization showed similar levels of correlation with IQ as with executive impairment. This raises questions about the specificity of the relationship between symptoms and executive impairment. General intellectual impairment is prevalent in schizophrenia and will in itself give rise to poor performance on executive tests without implying the presence of a specific neuropsychological deficit (see Goldberg et al. 2001 for a review). The same reasoning suggests that, when correlations are found between symptoms and executive impairment, this could also reflect correlations with coexistent general intellectual impairment. Of course, IQ is far from perfect as a measure of general intellectual impairment, as it varies widely across normal individuals. Nor is IQ ideal as a non-executive control measure; executive function is variably but overall moderately highly correlated with IQ in normal subjects (e.g. Obonswain et al. 2002), and frontal lobe lesions tends to lower IQ, at least as measured on 'fluid' as opposed to 'crystallized' tests (Duncan et al. 1995). An extreme view is that executive function and (fluid) IQ are one and the same thing (Duncan, 1995). Given these complexities, as well as the relatively small number of studies we were able to find that included measures of IQ, our findings should probably not be regarded as discrediting the association between negative symptoms/disorganization and executive impairment, but they clearly indicate that general intellectual function ought to be taken into consideration in future studies.

The findings of this meta-analysis support the view that the correlation between executive impairment and schizophrenic symptoms is specific in another sense, that of showing distinct patterns of association with different executive tests. Thus, negative symptoms were associated with verbal fluency but considerably less so with the Stroop test, whereas disorganization showed the reverse pattern. These differences accord well with Liddle's (1987a, 2001; Liddle \& Morris, 1991) proposal that the psychomotor poverty syndrome is a form of frontal lobe apathy, leading to slowness and failure to generate actions, whereas the disorganization syndrome reflects a frontal disinhibition syndrome characterized chiefly by failure to inhibit prepotent responses. At the same time, both negative symptoms and disorganization showed significant correlations with the Trail Making Test, part B $(r=-0.24$ and -0.31$)$ and with the WCST $(-0.16$ and -0.20$)$. It might be possible to explain these failures of dissociation, however. Thus, the WCST is sensitive to both frontal and non-frontal lesions (e.g. Lezak et al. 2004) and so successful performance might be considered to require a range of different executive (and non-executive) cognitive process. Similarly, impairment on the Trail Making Test, part B can obviously be due to failure to inhibit prepotent responses, but performance on this test should also be sensitive to the occurrence of perseveration.

An aside to these findings is that the correlations between working memory impairment and both negative symptoms $(-0.14)$ and disorganization $(-0.12)$ fell into the 'small' range, and were among lowest levels of association seen in the study. In recent years working memory impairment has been regarded as a key explanatory neuropsychological construct in schizophrenia (e.g. Goldman-Rakic \& Selemon, 1997; Silver et al. 2003). Whatever merits this proposal has, our meta-analysis suggests that it has little role in explaining the symptoms of the disorder. This is despite the fact that we were scrupulous about including only tests that tapped the central executive component of working memory and not just Baddeley's (1986) two slave systems, the articulatory loop and the visuospatial sketch pad.

Neuropsychology is not the only way to investigate the 'frontal lobe' hypothesis of schizophrenic symptoms. Nevertheless, the other evidence, which derives essentially from functional imaging studies, is surprisingly limited. In the first study using modern voxel-based techniques, Liddle et al. (1992) found that negative symptoms were associated with underactivity in wide areas of the prefrontal cortex bilaterally, and that disorganization was significantly associated with underactivity in Broca's area on the left and its analogue in the right frontal lobe cortex (and also hyperactivity in the right anterior cingulate cortex). However, further studies have been approximately equally divided between those supporting and those failing to support the association with prefrontal abnormality (for a review, see McKenna, 2007). The even smaller number of functional imaging studies of formal thought disorder (e.g. McGuire et al. 1998; Kircher et al. 2001, 2002; Weinstein et al. 2006) tends to implicate the temporal lobes more than the frontal lobes. It thus seems that, although neuropsychological studies may have demonstrated a link between certain classes of schizophrenic symptoms and the dysexecutive syndrome, the related question of whether negative symptoms and disorganization are analogues of the apathetic and disinhibited forms of the frontal lobe syndrome remains unanswered.

\section{Declaration of Interest}

None. 


\section{References}

( ${ }^{*}$ indicates study in one of the meta-analyses)

*Addington J, Addington D (2000). Neurocognitive and social functioning in schizophrenia : a 2.5 year follow-up study. Schizophrenia Research 44, 47-56.

*Addington J, Addington D, Maticka-Tyndale E (1991). Cognitive functioning and positive and negative symptoms in schizophrenia. Schizophrenia Research 5, 123-134.

*Allen DN, Anastasiou A, Goldstein G, Gilbertson M, van Kammen DP (2000). Influence of haloperidol on the relationship of frontal lobe function to psychomotor poverty and disorganization syndromes. Psychiatry Research 93, 33-39.

Baddeley AD (1986). Working Memory. Clarendon Press: Oxford.

*Barch DM, Carter CS, Perlstein W, Baird J, Cohen JD, Schooler N (1999). Increased Stroop facilitation effects in schizophrenia are not due to increased automatic spreading activation. Schizophrenia Research 39, 51-64.

*Barrera A, Hodges JR, McKenna PJ, Berrios GE (2005). Formal thought disorder in schizophrenia: an executive or a semantic deficit? Psychological Medicine 35, 121-132.

*Basso MR, Nasrallah HA, Olson SC, Bornstein RA (1998). Neuropsychological correlates of negative, disorganized and psychotic symptoms in schizophrenia. Schizophrenia Research 31, 99-111.

*Baxter RD, Liddle PF (1998). Neuropsychological deficits associated with schizophrenic syndromes. Schizophrenia Research 30, 239-249.

*Bell MD, Lysaker PH, Milstein RM, Beam-Goulet JL (1994). Concurrent validity of the cognitive component of schizophrenia: relationship of PANSS scores to neuropsychological assessments. Psychiatry Research 54, 51-58.

*Berman I, Viegner B, Merson A, Allan E, Pappas D, Green AI (1997). Differential relationships between positive and negative symptoms and neuropsychological deficits in schizophrenia. Schizophrenia Research 25, 1-10.

*Bersani G, Clemente R, Gherardelli S, Pancheri P (2004). Deficit of executive functions in schizophrenia: relationship to neurological soft signs and psychopathology. Psychopathology 37, 118-123.

*Bilder RM, Goldman RS, Robinson D, Reiter G, Bell L, Bates JA, Pappadopulos E, Wilson DF, Alvir JMJ, Woerner MG, Geisler S, Kane JM, Lieberman JA (2000). Neuropsychology of first episode schizophrenia: initial characterization and clinical correlates. American Journal of Psychiatry 157, 549-559.

*Bilder RM, Mukherjee S, Rieder RO, Pandurangi AK (1985). Symptomatic and neuropsychological components of defect states. Schizophrenia Bulletin 11, 409-417.

Borenstein M, Hedges L, Higgins J, Rothstein H (2006). Comprehensive Meta-Analysis, Version 2. Biostat: Englewood, NJ.

*Bozikas VP, Kosmidis MH, Kiosseoglou G, Karavatos A (2006). Neuropsychological profile of cognitively impaired patients with schizophrenia. Comprehensive Psychiatry 47, 136-143.
*Braff DL, Heaton R, Kuck J, Cullum M, Moranville J, Grant I, Zisook S (1991). The generalized pattern of neuropsychological deficits in outpatients with chronic schizophrenia with heterogeneous Wisconsin Card Sorting Test results. Archives of General Psychiatry 48, 891-898.

${ }^{*}$ Brazo P, Marie RM, Halbecq I, Benali K, Segard L, Delamillieure P, Langlois-Thery S, Van Der Elst A, Thibaut F, Petit M, Dollfus S (2002). Cognitive patterns in subtypes of schizophrenia. European Psychiatry 17, 155-162.

*Brebion G, Smith MJ, Amador X, Malaspina D, Gorman JM (1997). Clinical correlates of memory in schizophrenia: differential links between depression, positive and negative symptoms, and two types of memory impairment. American Journal of Psychiatry 154, 1538-1543.

*Brebion G, Smith M, Gorman JM, Malaspina D, Amador X (1998). Resistance to interference and positive symptomatology in schizophrenia. Cognitive Neuropsychiatry 3, 179-190.

*Brekke JS, Raine A, Thomson C (1995). Cognitive and psychopathological correlates of positive, negative, and disorganized symptoms in the schizophrenia spectrum. Psychiatry Research 57, 241-250.

*Brier A, Schreiber JL, Dyer J, Pickar D (1991). National Institute of Mental Health longitudinal study of chronic schizophrenia. Archives of General Psychiatry 48, 239-246.

*Brown KW, White T (1991). The association among negative symptoms, movement disorders, and frontal lobe psychological deficits in schizophrenic patients. Biological Psychiatry 30, 1182-1190.

Brown KW, White T (1992). Syndromes of chronic schizophrenia and some clinical correlates. British Journal of Psychiatry 161, 317-322.

*Bryson G, Whelahan HA, Bell M (2001). Memory and executive function impairments in deficit syndrome schizophrenia. Psychiatry Research 102, 29-37.

*Buchanan RW, Strauss ME, Kirkpatrick B, Holstein C, Brier A, Carpenter WT (1994). Neuropsychological impairments in deficit vs nondeficit forms of schizophrenia. Archives of General Psychiatry 51, 804-811.

*Butler RW, Jenkins MA, Sprock J, Braff DL (1992). Wisconsin Card Sorting Test deficits in chronic paranoid schizophrenia: evidence for a relatively discrete subgroup? Schizophrenia Research 7, 169-176.

${ }^{*}$ Cadenhead KS, Geyer MA, Butler RW, Perry W, Sprock J, Braff DL (1997). Information processing deficits of schizophrenia patients: relationship to clinical ratings, gender and medication status. Schizophrenia Research 28, $51-62$.

*Cameron AM, Oram J, Geffen GM, Kavanagh DJ, McGrath JJ, Geffen L (2002). Working memory correlates of three syndrome clusters in schizophrenia. Psychiatry Research 110, 49-61.

*Capleton RA (1996). Cognitive function in schizophrenia: association with negative and positive symptoms. Psychological Reports 78, 123-128.

Carpenter Jr. WT, Heinrichs DW, Wagman AM (1988). Deficit and nondeficit forms of schizophrenia: the concept. American Journal of Psychiatry 145, 578-583.

${ }^{*}$ Carstairs K, Okocha C, Hemsley D, Toone B, Sivakumar K (1995). An application of Shallice's response selection 
model to the symptoms of schizophrenia. Neurology, Psychiatry and Brain Research 3, 211-218.

Chaika E (1996). Intention, attention and deviant schizophrenic speech. In Communication and the Mentally Ill Patient: Developmental and Linguistic Approaches to Schizophrenia (ed. J. France and N. Muir), pp. 18-29. Jessica Kingsley: London.

*Chan RC, Chen EY, Law CW (2006). Specific executive dysfunction in patients with first-episode medicationnaive schizophrenia. Schizophrenia Research 82, 51-64.

*Chen EY, Lam LC, Chen RY, Nguyen DG (1996).

Negative symptoms, neurological signs and neuropsychological impairments in 204 Hong Kong Chinese patients with schizophrenia. British Journal of Psychiatry 168, 227-233.

${ }^{*}$ Chen YL, Chen YH, Lieh-Mak F (2000). Semantic verbal fluency deficit as a familial trait marker in schizophrenia. Psychiatry Research 95, 133-148.

*Clark O, O'Carroll RE (1998). An examination of the relationship between executive function, memory and rehabilitation status in schizophrenia. Neuropsychological Rehabilitation 8, 229-241.

${ }^{*}$ Cohen AS, Saperstein AM, Gold JM, Kirkpatrick B, Carpenter Jr. WT, Buchanan RW (2007). Neuropsychology of the deficit syndrome: new data and meta-analysis of findings to date. Schizophrenia Bulletin 33, 1201-1212.

*Cuesta MJ, Peralta V (1995). Cognitive disorders in the positive, negative, and disorganization syndromes of schizophrenia. Psychiatry Research 58, 227-235.

*Cuesta MJ, Peralta V, Caro F, Leon J (1995). Schizophrenic syndromes and Wisconsin Card Sorting Test dimensions. Psychiatry Research 58, 45-51.

*Daban C, Amado I, Baylé F, Gut A, Willard D, Bourdel M-C, Loo H, Olié J-P, Millet B, Krebs M-O, Poirier M-F (2002). Correlation between clinical syndromes and neurological tasks in unmedicated patients with recent onset schizophrenia. Psychiatry Research 113, 83-92.

Donohoe G, Robertson IH (2003). Can specific deficits in executive functioning explain the negative symptoms of schizophrenia? A review. Neurocase 9, 97-108.

*Duffy L, O'Carroll R (1994). Memory impairment in schizophrenia - a comparison with that observed in the alcoholic Korsakoff syndrome. Psychological Medicine 24, 155-165.

Duncan J (1995). Attention, intelligence and the frontal lobes. In The Cognitive Neurosciences (ed. M. S. Gazzaniga), pp. 721-733. MIT Press: Cambridge, MA.

Duncan J, Burgess P, Emslie H (1995). Fluid intelligence after frontal lobe lesions. Neuropsychologia 33, 261-268.

*Eckman PS, Shean GD (2000). Impairment in test performance and symptom dimensions of schizophrenia. Journal of Psychiatric Research 34, 147-153.

${ }^{*}$ Faber R, Reichstein MB (1981). Language dysfunction in schizophrenia. British Journal of Psychiatry 139, 519-522.

Fish FJ (1957). The classification of schizophrenia: the views of Kleist and his co-workers. Journal of Mental Science 103, 443-463.

*Flaum M, Andreasen NC, Swayze 2nd VW, O'Leary DS, Alliger RJ (1994). IQ and brain size in schizophrenia. Psychiatry Research 53, 243-257.
*Franke P, Maier W, Hain C, Klingler T (1992). Wisconsin Card Sorting Test: an indicator of vulnerability to schizophrenia? Schizophrenia Research 6, 243-249.

${ }^{*}$ Franke P, Maier W, Hardt J, Frieboes R, Lichtermann D, Hain C (1993). Assessment of frontal lobe functioning in schizophrenia and unipolar major depression. Psychopathology 26, 76-84.

Frith CD (1992). The Cognitive Neuropsychology of Schizophrenia. Erlbaum (UK) Taylor \& Francis: Hove.

${ }^{*}$ Galderisi S, Maj M, Mucci A, Cassano GB, Invernizzi G, Rossi A, Vita A, Dell'Osso L, Daneluzzo E, Pini S (2002). Historical, psychopathological, neurological, and neuropsychological aspects of deficit schizophrenia: a multicenter study. American Journal of Psychiatry 159, 983-990.

*Glahn DC, Cannon TD, Gur RE, Ragland JD, Gur RC (2000). Working memory constrains abstraction in schizophrenia. Biological Psychiatry 47, 34-42.

${ }^{*}$ Goldberg TE, Aloia MS, Gourevitch ML, Missar D, Pickar D, Weinberger DR (1998). Cognitive substrates of thought disorder. I. The semantic system. American Journal of Psychiatry 155, 1671-1676.

Goldberg TE, Gold J, David AD (2001). Neurocognitive deficits in schizophrenia. In Schizophrenia, 2nd edn (ed. S. R. Hirsch and D. R. Weinberger), pp. 168-186. Blackwell: Oxford.

*Goldberg TE, Ragland JD, Gold JM, Bigelow LB, Torrey EF, Weinberger DR (1990). Neuropsychological assessment of monozygotic twins discordant for schizophrenia. Archives of General Psychiatry 47, 1066-1072.

Goldman-Rakic PS, Selemon LD (1997). Functional and anatomical aspects of prefrontal pathology in schizophrenia. Schizophrenia Bulletin 23, 437-458.

*Good KP, Rabinowitz J, Whitehorn D, Harvey PD, DeSmedt G, Kopala LC (2004). The relationship of neuropsychological test performance with the PANSS in antipsychotic naive, first-episode psychosis patients. Schizophrenia Research 68, 11-19.

*Guillem F, Bicu M, Bloom D, Wolf M-A, Desautels R, Lalinec M, Krause D, Debruille JB (2001).

Neuropsychological impairments in the syndromes of schizophrenia : a comparison between different dimensional models. Brain and Cognition 46, 153-159.

${ }^{*}$ Hammer MA, Katsanis J, Iacono WG (1995). The relationship between negative symptoms and neuropsychological performance. Biological Psychiatry 37, 828-830.

Harrison PJ, Lewis DA (2003). Neuropathology of schizophrenia. In Schizophrenia, 2nd edn (ed. S. R. Hirsch and D. R. Weinberger), pp. 310-325. Blackwell: Oxford.

*Hawkins KA, Hoffman RE, Quinlan DM, Rakfeldt J, Docherty NM, Sledge WH (1997). Cognition, negative symptoms, and diagnosis: a comparison of schizophrenic, bipolar, and control samples. Journal of Neuropsychiatry and Clinical Neuroscience 9, 81-89.

Heinz A, Romero B, Weinberger DR (2004). Functional mapping with single-photon emission computed tomography and positron emission tomography. In Schizophrenia: From Neuroimaging to Neuroscience 
(ed. S. M. Lawrie, D. R. Weinberger and E. C. Johnstone), pp. 167-212. Oxford University Press: Oxford.

*Heydebrand G, Weiser M, Rabinowitz J, Hoff AL, DeLisi LE, Csernansky JG (2004). Correlates of cognitive deficits in first episode schizophrenia. Schizophrenia Research 68, 1-9.

Hill K, Mann L, Laws KR, Stephenson CM, Nimmo-Smith I, McKenna PJ (2004). Hypofrontality in schizophrenia: a meta-analysis of functional imaging studies. Acta Psychiatrica Scandinavica 110, 243-256.

*Himelhoch S, Taylor SF, Goldman RS, Tandon R (1996). Frontal lobe tasks, antipsychotic medication, and schizophrenia syndromes. Biological Psychiatry 39, 227-229.

*Horan WP, Blanchard JJ (2003). Neurocognitive, social, and emotional dysfunction in deficit syndrome schizophrenia. Schizophrenia Research 65, 125-137.

Howell DC (1997). Statistical Methods for Psychology, 4th edn. Duxbury Press: Belmont, CA.

Johnson BT (1993). DSTAT 1.10: Software for the Meta-analytic Review of Research Literatures. Erlbaum: Hillsdale, NJ.

*Joyce E, Hutton S, Mutsatsa S, Gibbins H, Webb E, Paul S, Robbins T, Barnes T (2002). Executive dysfunction in first-episode schizophrenia and relationship to duration of untreated psychosis: the West London Study. British Journal of Psychiatry 181 (Suppl. 43), s38-s44.

Kircher TT, Liddle PF, Brammer MJ, Williams SC, Murray RM, McGuire PK (2001). Neural correlates of formal thought disorder in schizophrenia: preliminary findings from a functional magnetic resonance imaging study. Archives of General Psychiatry 58, 769-774.

Kircher TT, Liddle PF, Brammer MJ, Williams SC, Murray RM, McGuire PK (2002). Reversed lateralization of temporal activation during speech production in thought disordered patients with schizophrenia. Psychological Medicine 32, 439-449.

Kirkpatrick B, Buchanan RW, Ross DE, Carpenter Jr. WT (2001). A separate disease within the syndrome of schizophrenia. Archives of General Psychiatry 58, 165-171.

Kleist K (1960). Schizophrenic symptoms and cerebral pathology. Journal of Mental Science 106, 246-255.

*Klingberg S, Wittorf A, Wiedemann G (2006). Disorganization and cognitive impairment in schizophrenia: independent symptom dimensions? European Archives of Psychiatry and Clinical Neuroscience 256, 532-540.

*Landre NA, Taylor MA (1995). Formal thought disorder in schizophrenia. Linguistic, attentional, and intellectual correlates. Journal of Nervous and Mental Disease 183, 673-680.

*Langdon R, Coltheart M, Ward PB, Catts SV (2002). Disturbed communication in schizophrenia: the role of poor pragmatics and poor mind-reading. Psychological Medicine 32, 1273-1284.

Laws KR (1999). A meta-analytic review of Wisconsin Card Sort studies in schizophrenia: general intellectual deficit in disguise. Cognitive Neuropsychiatry 4, 1-35.

Lezak MD, Howieson DB, Loring DW (2004). Neuropsychological Assessment, 3rd edn. Oxford University Press: Oxford.
*Liddle PF (1987a). Schizophrenic syndromes, cognitive performance and neurological dysfunction. Psychological Medicine 17, 49-57.

Liddle PF (1987b). The symptoms of chronic schizophrenia : a re-examination of the positive-negative dichotomy. British Journal of Psychiatry 151, 145-151.

Liddle PF (2001). Disordered Mind and Brain. Gaskell: London.

Liddle PF, Friston KJ, Frith CD, Hirsch SR, Jones T, Frackowiak RSJ (1992). Patterns of cerebral blood flow in schizophrenia. British Journal of Psychiatry 160, 179-186.

${ }^{*}$ Liddle PF, Morris DL (1991). Schizophrenic syndromes and frontal lobe performance. British Journal of Psychiatry 158, 340-345.

*Lucas S, Fitzgerald D, Redoblado-Hodge MA, Anderson J, Sanbrook M, Harris A, Brennan J (2004).

Neuropsychological correlates of symptom profiles in first episode schizophrenia. Schizophrenia Research 71, 323-330.

* Mahurin RK, Velligan DI, Hazleton B, Davis JM, Eckert S, Miller AL (2006). Trailmaking Test errors and executive function in schizophrenia and depression. Clinical Neuropsychologist 20, 271-288.

* Maron LM, Carlson MD, Minassian A, Perry W (2004). A process approach to verbal fluency in patients with schizophrenia. Schizophrenia Research 68, 105-106.

McGrath J (1991). Ordering thoughts on thought disorder. British Journal of Psychiatry 158, 307-316.

McGuire PK, Quested DJ, Spence SA, Murray RM, Frith CD, Liddle PF (1998). Pathophysiology of 'positive' thought disorder in schizophrenia. British Journal of Psychiatry 173, 231-235.

McKenna P, Oh T (2005). Schizophrenic Speech: Making Sense of Bathroots and Ponds that Fall in Doorways. Cambridge University Press: Cambridge.

McKenna PJ (2007). Schizophrenia and Related Syndromes, 2nd edn. Routledge: Hove.

*Merriam AE, Kay SR, Opler LA, Kushner SF, van Praag HM (1990). Neurological signs and the positive-negative dimension in schizophrenia. Biological Psychiatry 28, 181-192.

*Mohamed S, Paulsen JS, O'Leary D, Arndt S, Andreasen NC (1999). Generalized cognitive deficits in schizophrenia: a study of first episode patients. Archives of General Psychiatry 56, 749-754.

*Morice R, Delahunty A (1996). Frontal/executive impairments in schizophrenia. Schizophrenia Bulletin 22, 125-137.

*Moritz S, Andresen B, Jacobsen D, Mersmann K, Wilke U, Lambert M, Naber D, Kausz M (2001). Neuropsychological correlates of schizophrenic syndromes in patients treated with atypical neuroleptics. European Psychiatry 16, 354-361.

*Morris RG, Rushe T, Woodruffe PW, Murray RM (1995). Problem solving in schizophrenia: a specific deficit in planning ability. Schizophrenia Research 14, 235-246.

*Mortimer AM, Bentham P, McKay AP, Clare L, Eastwood N, McKenna PJ (1996). Delusions in schizophrenia: a phenomenological and psychological exploration. Cognitive Neuropsychiatry 1, 289-304.

${ }^{*}$ Muller BW, Sartory G, Bender S (2004). Neuropsychological deficits and concomitant clinical 
symptoms in schizophrenia. European Psychologist 9, 96-106.

*Nelson HE, Pantelis C, Carruthers K, Speller J, Baxendale S, Barnes TR (1990). Cognitive functioning and symptomatology in chronic schizophrenia. Psychological Medicine 20, 357-365.

Nieuwenstein MR, Aleman A, Dehaan EHF (2001). Relationship between symptom dimensions and neurocognitive functioning in schizophrenia: a meta-analysis of WCST and CPT studies. Journal of Psychiatric Research 35, 119-125.

*Norman RMG, Malla AK, Morrison-Stewart SL, Helmes E, Williamson PC, Thomas J, Cortese L (1997).

Neuropsychological correlates of syndromes in schizophrenia. British Journal of Psychiatry 170, 134-139.

Obonsawin MC, Crawford JR, Page J, Chalmers P, Cochrane R, Low G (2002). Performance on tests of frontal lobe function reflect general intellectual ability. Neuropsychologia 40, 970-977.

*O'Leary DS, Flaum M, Kesler ML, Flashman LA, Arndt S, Andreasen NC (2000). Cognitive correlates of negative, disorganized and psychotic symptom dimensions of schizophrenia. Journal of Neuropsychiatry and Clinical Neurosciences 12, 4-15.

*Parellada E, Catarineu S, Catafau A, Bernardo M, Lomena F (2000). Psychopathology and Wisconsin Card Sorting Test performance in young unmedicated schizophrenic patients. Psychopathology 33, 14-18.

*Perry W, Braff DL (1998). A multimethod approach to assessing perseverations in schizophrenia patients. Schizophrenia Research 33, 69-77.

*Pollice R, Roncone R, Falloon IRH, Mazza M, De Risio A, Necozione S, Morosini P, Casacchia M (2002). Is theory of mind in schizophrenia more strongly associated with clinical and social deficits than with neurocognitive deficits? Psychopathology 35, 280-288.

*Pukrop R, Matuschek E, Ruhrmann S, Brockhaus-Dumke A, Tendolkar I, Bertsch A, Klosterkotter J (2003). Dimensions of working memory dysfunction in schizophrenia. Schizophrenia Research 62, 259-268.

* Ragland JD, Censits DM, Gur RC, Glahn DC, Gallacher F, Gur RE (1996). Assessing declarative memory in schizophrenia using Wisconsin Card Sorting Test stimuli : the Paired Associate Recognition Test. Psychiatry Research 60, 135-145.

*Robert PH, Lafont V, Medicin I, Berthet L, Thauby S, Baudu C, Darcourt G (1998). Clustering and switching strategies in verbal fluency tasks: comparison between schizophrenics and healthy adults. Journal of the International Neuropsychological Society 4, 539-546.

*Rosse RB, Schwartz BL, Kim SY, Deutsch SI (1993). Correlation between antisaccade and Wisconsin Card Sorting Test performance in schizophrenia. American Journal of Psychiatry 150, 333-335.

${ }^{*}$ Rossi A, Mancini F, Stratta P, Mattei P, Gismondi R, Pozzi F, Casacchia M (1997). Risperidone, negative symptoms and cognitive deficit in schizophrenia: an open study. Acta Psychiatrica Scandinavica 95, 40-43.

${ }^{*}$ Rund BR, Melle I, Friis S, Larsen TK, Midboe LJ, Opjordsmoen S, Simonsen E, Vaglum P, McGlashan T
(2004). Neurocognitive dysfunction in first-episode psychosis: correlates with symptoms, premorbid adjustment, and duration of untreated psychosis. American Journal of Psychiatry 161, 466-472.

*Sachdev P, Hume F, Toohey P, Doutney C (1996). Negative symptoms, cognitive dysfunction, tardive akathisia and tardive dyskinesia. Acta Psychiatrica Scandinavica 93, 451-459.

*Sanfilipo M, Lafargue T, Rusinek H, Arena L, Loneragan C, Lautin A, Rotrosen J, Wolkin A (2002). Cognitive performance in schizophrenia: relationship to regional brain volumes and psychiatric symptoms. Psychiatry Research 116, 1-23.

*Saoud M, Hueber T, Mandran H, Dalery J, d'Amato T (1998). Olfactory identification deficiency and WCST performance in men with schizophrenia. Psychiatry Research 81, 251-257.

*Schuepbach D, Keshavan MS, Kmiec JA, Sweeney JA (2002). Negative symptom resolution and improvements in specific cognitive deficits after acute treatment in first-episode schizophrenia. Schizophrenia Research 53, 249-261.

*Seckinger RA, Goudsmit N, Coleman E, HarkavyFriedman J, Yale S, Rosenfield PJ, Malaspina D (2004). Olfactory identification and WAIS-R performance in deficit and nondeficit schizophrenia. Schizophrenia Research 69, 55-65.

*Silver H, Feldman P, Bilker W, Gur RC (2003). Working memory deficit as a core neuropsychological dysfunction in schizophrenia. American Journal of Psychiatry 160, 1809-1816.

*Simon AE, Giacomini V, Ferrero F, Mohr S (2003). Is executive function associated with symptom severity in schizophrenia? European Archives of Psychiatry and Clinical Neuroscience 253, 216-218.

*Stirling J, Hellewell J, Blakey A, Deakin W (2006). Thought disorder in schizophrenia is associated with both executive dysfunction and circumscribed impairments in semantic function. Psychological Medicine 36, 475-484.

*Stirling J, White C, Lewis S, Hopkins R, Tantam D, Huddy A, Montague L (2003). Neurocognitive function and outcome in first-episode schizophrenia: a 10-year follow-up of an epidemiological cohort. Schizophrenia Research 65, 75-86.

*Stolar N, Berenbaum H, Banich MT, Barch D (1994). Neuropsychological correlates of alogia and affective flattening in schizophrenia. Biological Psychiatry 35, 164-172.

*Strauss ME, Buchanan RW, Hale J (1993). Relations between attentional deficits and clinical symptoms in schizophrenic outpatients. Psychiatry Research 47, 205-213.

*Sullivan EV, Shear PK, Zipursky RB, Sagar HJ, Pfefferbaum A (1994). A deficit profile of executive, memory, and motor functions in schizophrenia. Biological Psychiatry 36, 641-653.

*Tandon R, DeQuardo JR, Taylor SF, McGrath M, Jibson M, Eiser A, Goldman M (2000). Phasic and enduring negative symptoms in schizophrenia: biological markers and relationship to outcome. Schizophrenia Research 45, 191-201. 
*Tiryaki A, Yazici MK, Anil AE, Kabakci E, Karaagaoglu E, Gogus AR (2003). Examination of the characteristics of the deficit schizophrenia patients. European Archives of Psychiatry Clinical Neuroscience 253, 221-227.

*Tonioni S, Michelin P, Sartori GE (1995).

Neuropsychological survey of the positive and negative symptoms of schizophrenia [in Italian]. Giornale Italiano di Psicología 22, 395-416.

*Twamley EW, Palmer BW, Jeste DV, Taylor MJ, Heaton RK (2006). Transient and executive function working memory in schizophrenia. Schizophrenia Research 87, 185-190.

*Van der Does AJ, Dingemans PM, Linszen DH, Nugter MA, Scholte WF (1993). Symptom dimensions and cognitive and social functioning in recent-onset schizophrenia. Psychological Medicine 23, 745-753.

*Verdoux H, Liraud F, Bourgeois M (1999). The association of neuropsychological deficits to clinical symptoms in first admission subjects with psychotic disorders. Schizophrenia Research 37, 198-201.

*Voruganti LN, Heslegrave RJ, Awad AG (1997).

Neurocognitive correlates of positive and negative syndromes in schizophrenia. Canadian Journal of Psychiatry 42, 1066-1071.

*Wang X, Yao S, Kirkpatrick B, Shi C, Yi J (2008).

Psychopathology and neuropsychological impairments in deficit and nondeficit schizophrenia of Chinese origin. Psychiatry Research 158, 195-205.

*Waters FA, Badcock JC, Maybery MT, Michie PT (2003). Inhibition in schizophrenia: association with auditory hallucinations. Schizophrenia Research 62, 275-280.

Weinberger DR (1988). Schizophrenia and the frontal lobe. Trends in Neuroscience 11, 367-370.

Weinstein S, Werker JF, Vouloumanos A, Woodward TS, Ngan ET (2006). Do you hear what I hear? Neural correlates of thought disorder during listening to speech in schizophrenia. Schizophrenia Research 86, 130-137.

${ }^{*}$ Woodward TS, Ruff CC, Thornton AE, Moritz S, Liddle PF (2003). Methodological considerations regarding the association of Stroop and verbal fluency performance with the symptoms of schizophrenia. Schizophrenia Research 61, 207-214.

*Zakzanis KK (1998). Neuropsychological correlates of positive vs. negative schizophrenic symptomatology. Schizophrenia Research 29, 227-233. 